\title{
Article \\ UHPLC-MS Method for the Analysis of the Molecular Adjuvant Sulfavant A
}

\author{
Genoveffa Nuzzo ${ }^{1, *,+}+\mathbb{D}_{\text {, Emiliano Manzo }}{ }^{1,+}+\mathbb{D}$, Marcello Ziaco ${ }^{2}$, Laura Fioretto ${ }^{1}$, Ana Margarida Campos ${ }^{1,3}$, \\ Carmela Gallo ${ }^{1} \mathbb{D}$, Giuliana d'Ippolito ${ }^{1}$ and Angelo Fontana ${ }^{1,4} \mathbb{D}$
}

1 Bio-Organic Chemistry Unit, National Research Council-Institute of Bio-Molecular Chemistry (ICB-CNR), Via Campi Flegrei 34, 80078 Pozzuoli, Italy; emanzo@icb.cnr.it (E.M.); 1.fioretto@icb.cnr.it (L.F.); am.campos@ibp.cnr.it (A.M.C.); carmen.gallo@icb.cnr.it (C.G.); gdippolito@icb.cnr.it (G.d.); afontana@icb.cnr.it (A.F.)

2 BioSearch Srl., Villa Comunale c/o Stazione Zoologica "A.Dohrn", 80121 Napoli, Italy; m.ziaco@icb.cnr.it Institute of Protein Biochemistry, National Research Council, Via Pietro Castellino 111, 80131 Naples, Italy

4 Department of Biology, University of Napoli “Federico II”, Via Cupa Nuova Cinthia 21, 80126 Napoli, Italy

* Correspondence: nuzzo.genoveffa@icb.cnr.it

+ These authors contributed equally to this work.

Citation: Nuzzo, G.; Manzo, E.;

Ziaco, M.; Fioretto, L.; Campos, A.M.; Gallo, C.; d'Ippolito, G.; Fontana, A. UHPLC-MS Method for the Analysis of the Molecular Adjuvant Sulfavant A. Appl. Sci. 2021, 11, 1451. https:// doi.org/10.3390/app11041451

Academic Editor: Magdalena Biesaga Received: 7 January 2021

Accepted: 2 February 2021

Published: 5 February 202

Publisher's Note: MDPI stays neutral with regard to jurisdictional claims in published maps and institutional affiliations.

Copyright: (c) 2021 by the authors. Licensee MDPI, Basel, Switzerland. This article is an open access article distributed under the terms and conditions of the Creative Commons Attribution (CC BY) license (https:// creativecommons.org/licenses/by/ $4.0 /)$.

\begin{abstract}
A fast and sensitive method that is based on Ultra High Performance Liquid Chromatography coupled with High Resolution Mass Spectrometry (UHPLC-HRMS) for the measurement of Sulfavant A, a molecular adjuvant with a sulfolipid skeleton, is described. The method has been validated over the linearity range of $2.5-2000 \mathrm{ngmL}^{-1}$ using a deuterated derivative $\left(\mathrm{d}_{70}\right.$-Sulfavant A) as internal standard. Chromatographic separation is based on a UHPLC Kinetex ${ }^{\circledR} 2.6 \mu \mathrm{m}$ PS C18 column and a gradient of methanol in $0.32 \mathrm{mM}$ ammonium hydroxide solution buffered at $\mathrm{pH}$ 8. The lowest limit of quantification of Sulfavant A was $6.5 \mathrm{ngmL}^{-1}$. The analytical procedure was tested on an extract of mice lung spiked with 30,300, and $1500 \mathrm{ng}$ of Sulfavant A. The analysis revealed a precision and accuracy value (as a mean value of all the quality control samples analyzed) of $4.7 \%$ and $96 \%$ in $\mathrm{MeOH}$ and $6.4 \%$ and $93.4 \%$ in the lung extracts, respectively.
\end{abstract}

Keywords: sulfavant; sulfoquinovosyldiacylglycerols; sulfoglycolipids; mass spectrometry; UHPLCMS; lipids

\section{Introduction}

Sulfur-containing lipids and, in particular, sulfoquinovosyl-diacylglycerols (SQDGs) have been proposed as factors in inflammation, immunity and infection. However, despite their dissemination, fast and accurate ultra-performance liquid chromatography-mass spectrometry (UPLC-MS) or ultra high-performance liquid chromatography coupled with mass spectrometry (UHPLC-MS) methods for their quantification are still scarce and mostly focused on sulphate sterols [1-4] and sulfatides [5-7]. Most of the lipid analysis, also containing sulfolipids, as reported in the literature, are based on a shotgun lipidomic approach $[2,3]$ or traditional reverse phase (RP) - HPLC columns usually associated with complex mixtures of solvents used as eluents in order to obtain a good quality chromatogram [8].

In our ongoing drug discovery exploration for new active metabolites, we recently reported the immunomodulatory activity of 1,2-O-distearoyl-3-O- $\beta$-D-sulfoquinovosylglycerol, named Sulfavant A (1) (SULF A; Figure 1). SULF A is a synthetic glycolipid that is featured by a sugar unit of sulfoquinovose. The molecule is the prototype for a new class of molecular adjuvants inspired by natural $\alpha$-sulfoquinovosyl-diacylglycerols ( $\alpha$-SQDGs) occurring in photosynthetic organisms [9]. SULF A (1) triggers in vitro maturation of dendritic cells, the master control of innate immune response, and in in vivo antigenspecific immunization [10-15]. The initiation of a systemic immune response by the 
stimulation of innate immune cells correlates to adjuvanticity and Pattern Recognition Receptors (PRR) - mediated signaling. SULF A is under preclinical trials as a vaccine adjuvant and its efficacy has been already proven in a murine model of vaccine against melanoma [9]. Interestingly, the product is not cytotoxic, but treated mice do not show progress of the tumour for more than 10 days after subcutaneous injection of B16F10 melanoma cells.
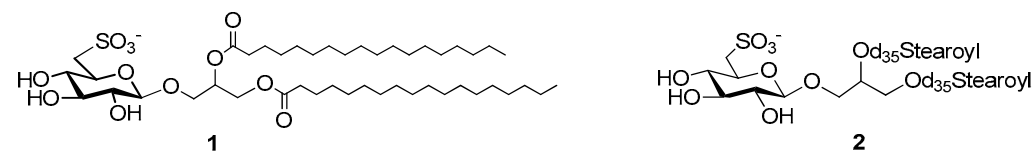

Figure 1. Chemical structure of Sulfavant A (1) deuterated Sulfavant A (2).

In the present study, we seek a robust and fast analytical method for the quantification of SULF A in biofluids and tissues during preclinical studies. To this aim, we report the implementation of a novel Ultra High-Performance Liquid Chromatography-High Resolution Mass Spectrometry (UHPLC-HRMS) method, together with the use of deuterated Sulfavant A (d $\mathrm{d}_{70}$-SULF A) (2) as internal standard (IS).

\section{Materials and Methods}

\subsection{Chemicals and Reagents}

SULF A (1) was prepared, as reported by Manzo et al. [9,10] and purified by HPLC before the analysis. The compound was eluted from a Phenomenex Phenl-Hexyl column $(250 \times 10 \mathrm{~mm}, 5 \mu \mathrm{m})$ in isocratic conditions using $\mathrm{MeOH} / \mathrm{H}_{2} \mathrm{O} 87: 13$ for $20 \mathrm{~min}$. and the solvent was removed by evaporation under reduced pressure. Chromatographic purification of synthetic lipids was carried out by a JASCO system (PU-2089 Plus quaternary gradient pump) that was equipped with a MD-2018 Plus photodiode array detector (JASCO Europe Srl, Cremella, Italy) and Sedex 85 high-sensitivity LT-ELS detector (SEDERE, Alfortville, Paris, France). The purity of 1 was verified by ${ }^{1} \mathrm{H}$ NMR and LCMS.

UHPLC-HRESIMS analysis was performed on Q-Exactive hybrid quadrupole-orbitrap mass spectrometer (Thermo Scientific, Waltham, MA, USA) that was equipped with an Infinity 1290 UHPLC System (Agilent Technologies, Santa Clara, CA, USA). Methanol, water, and 25\% ammonium hydroxide solution were all LC/MS grade. The chemical solvent and reagents were purchased from Merck Life Science S.r.l. (Milano, Italy).

\subsection{Synthetic Strategy of $d_{70}$-Sulfavant $A$}

The synthesis of $d_{70}$-SULF A was achieved by the ameliorated synthetic procedure for SULF A of Manzo et al. [10], which was adapted to the preparation of the analog totally deuterated on acyl portions; in detail, as compared to the literature procedure, deuterated stearic acid was used for the acylation of the $2^{\prime} 3^{\prime} 4^{\prime} 6^{\prime}$-O-tetracetyl- $\beta$-glucosyl- $R / S$-glycerol intermediate (Figure 2) $[10,14,15]$. Similarly to SULF A, compound 2 was purified by HPLC prior to use as an internal standard using the same experimental conditions.

\subsection{Ultra-High-Performance Liquid Chromatography/High Resolution Mass Spectrometry (UHPLC/HRMS)}

Chromatographic separations were achieved on UHPLC Kinetex ${ }^{\circledR} 2.6 \mu \mathrm{m}$ PS C18 $100 \AA$, LC Column $30 \times 2.1 \mathrm{~mm}$ (Phenomenex, Italy), at $28^{\circ} \mathrm{C}$ by a gradient elution of $0.32 \mathrm{mM}$ ammonium hydroxide solution $(0.005 \%)$, adjusted to $\mathrm{pH} 8.0$ by acetic acid, and methanol $(\mathrm{MeOH})$. Table 1 reports UHPLC gradient details. The flow rate was $0.5 \mathrm{~mL} \mathrm{~min}{ }^{-1}$. The injection volume was $4 \mu \mathrm{L}$, and the autosampler was maintained at $10^{\circ} \mathrm{C}$. MS analyses were carried out in electrospray ionization (ESI) negative mode with source parameters, as follows: spray voltage of $3.0 \mathrm{kV}$, capillary temperature of $320^{\circ} \mathrm{C}$, S-lens RF level of 60 , sheath gas flow rate of 50, and auxiliary gas flow rate of 30. Full MS scans were acquired over the range of 150-1800 Da with a mass resolution of 70,000. The target value (Automatic Gain Control-AGC) was $1 \times 10^{6}$ and the maximum allowed accumulation time (IT) was $100 \mathrm{~ms}$. 
For the data-dependent MS/MS (ddMS2) analyses, the peaks of interest were selected and fragmented with a stepped normalized energy of 20-40 eV. AGC was $1 \times 10^{5}$ with IT $75 \mathrm{~ms}$ and 17, 500 mass resolution.

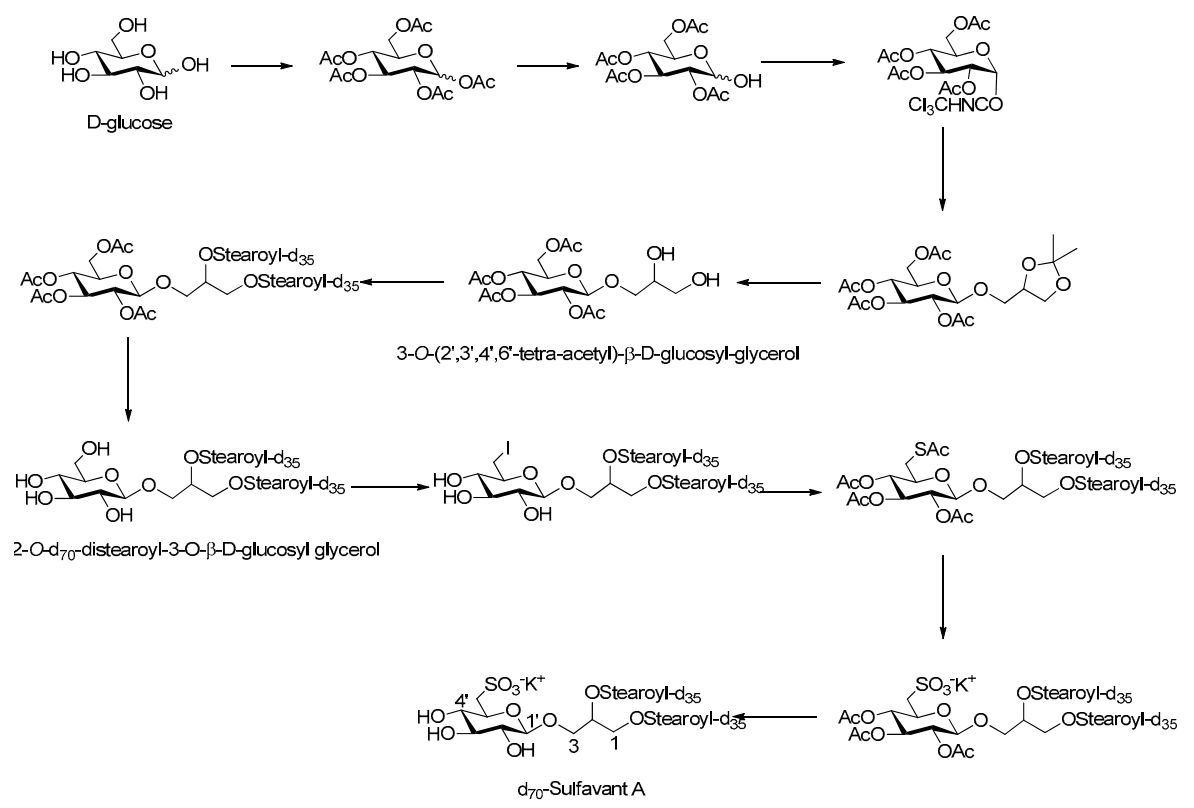

Figure 2. Chemical synthesis of deuterated Sulfavant A.

Table 1. Gradient program of the Ultra High Performance Liquid Chromatography (UHPLC) method.

\begin{tabular}{ccc}
\hline Time (min) & Mobile Phase A (\%) $\mathbf{a}^{\mathbf{a}}$ & Mobile Phase B (\%) $^{\mathbf{b}}$ \\
\hline 0 & 85 & 15 \\
1 & 85 & 15 \\
6 & 98 & 2 \\
8 & 100 & 0 \\
10 & 100 & 0 \\
11 & 85 & 15 \\
15 & 85 & 15
\end{tabular}

${ }^{\mathrm{a}}$ methanol $^{\mathrm{b}} 0.32 \mathrm{mM}$ ammonium hydroxide water solution (pH 8.0).

\subsection{Standard Preparation and Stock Solution}

SULF A and $d_{70}$-SULF A were dissolved in methanol to obtain stocks solutions at a concentration of $100 \mu \mathrm{g} \mathrm{mL} \mathrm{m}^{-1}$ stored at $-20^{\circ} \mathrm{C}$; the dissolution was performed by sonicating for $30 \mathrm{~min}$. at $30^{\circ} \mathrm{C}$. These two solutions were used to evaluate the linearity, calibration curve, limit of detection, and matrix effect. The evaluation of the above parameters is based on chromatograms of SULF A $\left(\mathrm{C}_{45} \mathrm{H}_{85} \mathrm{O}_{12} \mathrm{~S}^{-} ; \mathrm{m} / z\right.$ 849.57672) and $\mathrm{d}_{70}$-SULF A $\left(\mathrm{C}_{45} \mathrm{D}_{70} \mathrm{H}_{15} \mathrm{O}_{12} \mathrm{~S}^{-} ; m / z\right.$ 920.01609) that were obtained as base peak extraction at $m / z 849.576$ and 920.016, respectively, with a mass tolerance of 5 ppm (Figure 3). 


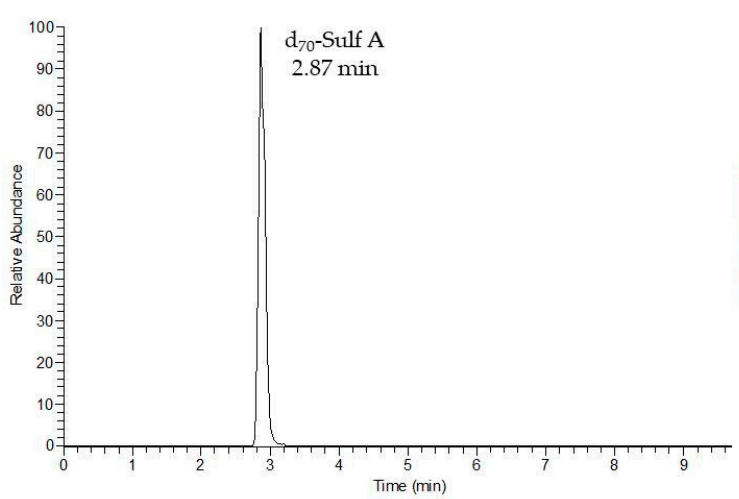

(a)

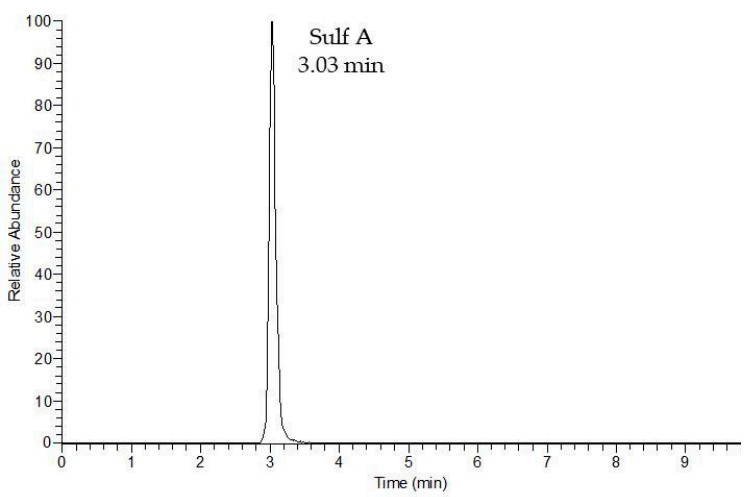

(b)

Figure 3. Chromatograms of $d_{70}$-Sulfavant $A($ (a) and Sulfavant $A(\mathbf{b})$ as base peak extraction at $m / z 920.016$ and 849.576 respectively, applying a mass tolerance of $5 \mathrm{ppm}$.

\subsection{Calibration Curve, Linearity and Detection and Quantitation Limits ( $L O D$ and LOQ)}

Before the analysis, the stock solution was sonicated for $30 \mathrm{~min}$. at $30^{\circ} \mathrm{C}$ The calibration curve was obtained by spiking increasing concentrations of standard solution at $1,2.5,5,10,50,100,500,1000$, and $2000 \mathrm{ngmL}^{-1}$. The average of three measurements was used for building up the calibration curve. The linearity of the calibration curve was also verified in the lipid extract matrix. Visual definition and the approach based on the

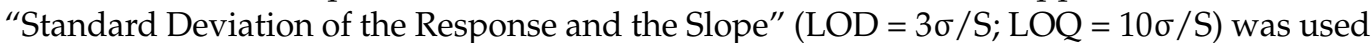
in order to establish detection and quantitation limit [16].

\subsection{Method Validation: Intra-and Inter-Day Accuracy and Precision}

Three quality control (QC) samples of SULF A were prepared to validate the method: low-concentration $\left(30 \mathrm{ngmL}^{-1}\right)$, medium-concentration $\left(300 \mathrm{ngmL}^{-1}\right)$, and high-concentration $\left(1500 \mathrm{ngmL}^{-1}\right)$. Validation for intra-day and inter-day assay accuracy and precision was assessed on three independent days while using a triplicate of three QC. Each batch of runs comprised mobile phase blanks, calibrators (eight samples spanning the range of 2.5-2000 $\mathrm{ngmL}^{-1}$ ), and quality control samples. Intra-day and inter-day accuracy and precision were determined by obtaining the mean concentration of the quality control samples from the calibration curve and the percent accuracy and coefficient of variation. The precision was expressed as a coefficient of variation $[\mathrm{CV}=$ (standard deviation $/ \mathrm{measured}$ mean concentration) $\times 100$ ], while the accuracy was expressed as [measured mean concentration/nominal concentration] $\times 100$. The overall method accuracy and precision were determined by calculating the mean of accuracy and mean of the precision estimates, respectively, of all the quality control samples.

\subsection{Evaluation of Matrix Effect on Mice Lung Extracts}

The matrix effect (ME) was assessed on mice lung tissue post-extraction. Lipid extracts were achieved from five different frozen samples by homogenization of the tissues in $\mathrm{MeOH}(300 \mu \mathrm{L})$ at $12{ }^{\circ} \mathrm{C}$ for $2 \mathrm{~min}$. and then following with MTBE extraction [17]. In detail, $1000 \mu \mathrm{L}$ of MTBE were added to the samples and then left to mix for 5 min. Later, $250 \mu \mathrm{L}$ of Milli-Q water was added and mixed again for $2 \mathrm{~min}$. Subsequently, to induce the phase separation, the sample was centrifuged at $1000 \mathrm{~g}$ for $10 \mathrm{~min}$. at $4{ }^{\circ} \mathrm{C}$ and the upper organic phase was recovered. Finally, the aqueous phase was re-extracted with MTBE, the upper phases combined, and the organic solvent removed under nitrogen stream. Each extract was weighted and resuspended in $\mathrm{MeOH}: \mathrm{CH}_{2} \mathrm{Cl}_{2}$ (4:1) and then diluted with $\mathrm{MeOH}$ for LC/MS analysis.

Three different concentrations of SULF A $\left(30,300\right.$, and $\left.1500 \mathrm{ngmL}^{-1}\right)$ were spiked into $50 \mu \mathrm{g} \mathrm{mL}^{-1}$ of lipid extracts, together with $50 \mathrm{ngmL}^{-1}$ of IS ( $\mathrm{d}_{70}$-SULF A), in order to evaluate normalized matrix effect (nME). Each concentration was compared with the 
corresponding solution in pure $\mathrm{MeOH}$. When considering peak area as instrument response, the percentage of nME was calculated, as reported in [18]:

$$
\mathrm{nME} \%=\left[\left(\mathrm{A}_{\text {solvent }} / \mathrm{IS}_{\text {solvent }}\right) /\left(\mathrm{A}_{\text {matrix }} / \mathrm{IS}_{\text {matrix }}\right)-1\right] \times 100
$$

in which $\mathrm{A}_{\text {solvent }}=$ peak area of the analyte SULF $\mathrm{A}$ in $\mathrm{MeOH} ; \mathrm{A}_{\text {matrix }}=$ peak area of the analyte SULF A in the post-extraction spiked matrix; IS solvent = peak area of the Internal Standard $\mathrm{d}_{70}-\mathrm{SULF} \mathrm{A}$ in MeOH ; and, IS matrix $=$ peak area of the Internal Standard $\mathrm{d}_{70}-\mathrm{SULF}$ $\mathrm{A}$ in the post-extraction spiked matrix.

Moreover, standards solutions at 2.5, 5, 10, 50, 100, 500, 1000, and $2000 \mathrm{ngmL}^{-1}$ were also prepared in matrix ( $50 \mu \mathrm{g} \mathrm{mL}^{-1}$ of mice lung lipid extract) in order to evaluate whether the matrix effect (ME) affected the slope of the calibration curve. The average of three measurements was used. Chromatograms of SULF A and $\mathrm{d}_{70}$-SULF A (as in MeOH) were obtained as base peak extraction at $m / z 849.576$ and 920.016, respectively, applying a mass tolerance of 5 ppm.

\section{Results and Discussion}

\subsection{Synthesis and Preparation of $d_{70}$-Sulfavant $A$}

The synthesis of $d_{70}$-SULF $A$ was achieved by the ameliorated synthetic strategy of Manzo et al. [10], which was adapted to the preparation of the analog with deuterated fatty acids (Figure 2). In detail, the procedure started with acetylation of D-glucose, followed by selective anomeric deacetylation by benzylamine. Coupling with $1,2-\mathrm{O}$-isopropylidene glycerol by trichloroacetimidate methodology $[14,15,19,20]$ gave $3-O-\left(2^{\prime}, 3^{\prime}, 4^{\prime}, 6^{\prime}\right.$-tetra-acetyl)$\beta$-D-glucosyl-glycerol that was condensed with $\mathrm{d}_{35}$-stearic acid in order to obtain the intermediate 1,2-O- $\mathrm{d}_{70}$-distearoyl-3-O- $\beta$-D-glucosyl glycerol. The sulfonation of the $6^{\prime}-$ carbon through an iodinate derivative in agreement with Manzo et al. [10] was performed to finally obtain $\mathrm{d}_{70}$-SULF A after the last hydrazinolysis step.

\subsection{Method Development}

Many of the studies of ultra- and ultra-high-performance liquid chromatography-mass spectrometry (UPLC- and UHPLC-MS) methods have addressed analysis of lipids [17,21]. However, no specific method for sulfoglycolipids has been reported so far.

UHPLC Kinetex ${ }^{\circledR}$ PS C18 column is a reversed-phase product that is recommended by the manufacturer for the analysis of polar compounds and weakly acidic compounds. We tested several eluting conditions with gradients of methanol with aqueous buffers at different $\mathrm{pH}$ and temperatures to optimize the chromatographic result for SULF A and $\mathrm{d}_{70}$-SULF A. The best result in terms of sensitivity, shape of the peak and retention time was obtained with a short gradient (run time $10 \mathrm{~min}$.) of increasing amount of methanol in $0.32 \mathrm{mM}$ ammonium hydroxide solution $(0.005 \%)$, adjusted to $\mathrm{pH} 8.0$ by acetic acid, at $28{ }^{\circ} \mathrm{C}$. Deuterated analogue of SULF A (2), synthesized in-house, was also used during the tests as internal standard (IS). Figure 3 shows chromatograms obtained by base peak extraction of SULF A (analyte) and $\mathrm{d}_{70}$-SULF A (IS). The IS and the analyte eluted with a slightly different retention time due to the isotope effect at 2.9 and $3.0 \mathrm{~min}$., respectively. The quantitation (LOQ) and detection (LOD) limits were $6.5 \mathrm{ngmL}^{-1}$ and $1.9 \mathrm{ngmL}^{-1}$, respectively, both established in methanol.

\subsection{Linearity, Accuracy, Precision and Matrix Effect}

The liquid chromatography-mass spectrometry (LC-MS) method was validated for linearity and by an evaluation of intra-and inter-day precision and accuracy in accordance with the currently-approved EMEA and FDA guidelines for the validation of bioanalytical methods [22,23]. Moreover, with the aim to demonstrate the consistency and robustness for the analysis of biological samples, we also tested the above-mentioned parameters in five different replicates of lipid extracts derived from mice lung tissues.

Samples of SULF A and $d_{70}$-SULF A were tested in triplicates between 1 and $2000 \mathrm{ngmL}^{-1}$. The resulting calibration curve was found to be linear in the concentration range between 
2.5 and 2000 ngmL $^{-1}$, as shown in Figure 4. Analogously, SULF A and $d_{70}$-SULF A were spiked at the maximum concentration into $\mathrm{MeOH}$ and in a lipid extract of mice lung in $\mathrm{MeOH}$ in order to evaluate matrix effect (one of the five extracts available). Samples of the two calibration curves (in pure $\mathrm{MeOH}$ and in matrix) were carried out by dilution from the more concentrated solution. Table 2 outlines the slope values and $\mathrm{R}^{2}$ parameters of the calibration curves acquired at different days (T0 and T48). The $\mathrm{R}^{2}$ was found to be 0.999 and stable during the days (slight differences in the slope could be appointed to the variability linked to the instrument response). The difference in the mean ordinate between SULF A and $d_{70}$-SULF $A$ is in agreement with the isotope effect that can cause a different degree of ion suppression. However, although the ionization and chromatographic response was not identical, the peak area ratio of the analyte versus the IS was constant over the range of tested concentrations, with a correlation coefficient $\left(\mathrm{r}^{2}\right)$ that is always higher than 0.9991 .

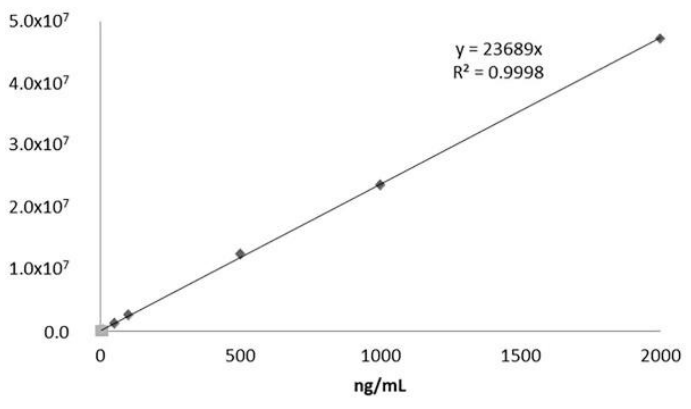

(a)

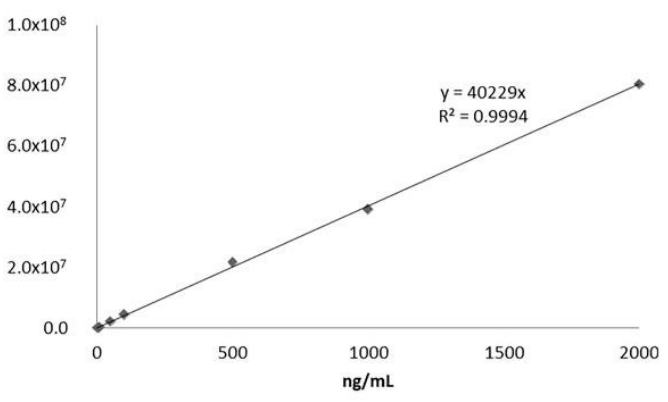

(b)

Figure 4. Calibration curve of $d_{70}$-Sulfavant $A(\mathbf{a})$ and Sulfavant $A(\mathbf{b})$.

Table 2. Calibration curve of $d_{70}$-Sulfavant $A$ and Sulfavant $A$ at $\mathrm{T} 0$ and $\mathrm{T} 48$, both in $\mathrm{MeOH}$ and in matrix.

\begin{tabular}{ccccc}
\hline & \multicolumn{2}{c}{ T0 } & \multicolumn{2}{c}{ T48 } \\
\hline & MeOH & Matrix & MeOH & Matrix \\
\hline \multirow{2}{*}{ SULF A } & $\mathrm{y}=40229 \mathrm{x}$ & $\mathrm{y}=47981 \mathrm{x}$ & $\mathrm{y}=50537 \mathrm{x}$ & $\mathrm{y}=46508 \mathrm{x}$ \\
& $\mathrm{R}^{2}=0.9996$ & $\mathrm{R}^{2}=0.9997$ & $\mathrm{R}^{2}=0.9991$ & $\mathrm{R}^{2}=0.9993$ \\
\hline \multirow{2}{*}{$\mathrm{d}_{\mathbf{7 0}}$-SULF A } & $\mathrm{y}=23689 \mathrm{x}$ & $\mathrm{y}=24546 \mathrm{x}$ & $\mathrm{y}=28250 \mathrm{x}$ & $\mathrm{y}=24185 \mathrm{x}$ \\
& $\mathrm{R}^{2}=0.9998$ & $\mathrm{R}^{2}=0.9991$ & $\mathrm{R}^{2}=1$ & $\mathrm{R}^{2}=0.9996$ \\
\hline
\end{tabular}

The matrix effect (ME) is one of the most important parameters to investigate during the development of an analytical method. In order to evaluate the ME, five mice lung lipid extracts were aliquoted and spiked with three different quantities (30, 300, and $1500 \mathrm{ng}$ ) of SULF A (Figure 5), while the same known amount of $d_{70}$-SULF A (50 ng per sample) as IS was added to compare the area of the analyte in matrix with the area measured in pure $\mathrm{MeOH}$ (normalized matrix effect-nME). A higher $\mathrm{CV}$ was observed for the high concentrations in comparisons with the low ones, as can be seen in Table 3. However, all of the datasets (intra- and inter-day) passed the 15\% acceptance criterion, with an overall nME average of $10 \%$. This finding was the first evidence of the robustness of the proposed analytical procedure. 

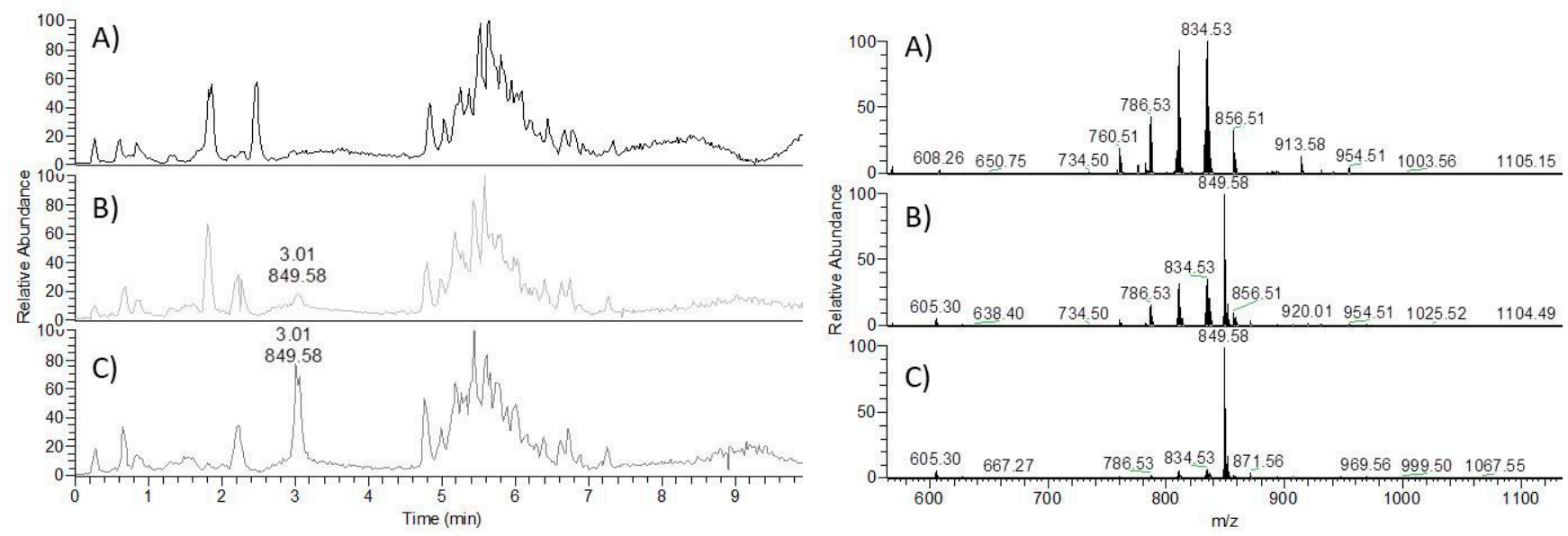

Figure 5. Chromatograms and mass spectrum acquired at $3 \mathrm{~min}$. of pure matrix extract (A), matrix spiked with $300 \mathrm{ng}$ (B) and $1500 \mathrm{ng}(\mathbf{C})$ of Sulfavant A. Chromatograms were obtained as $m / z$ mass range between 400 and 1200.

Table 3. Accuracy and precision of quality control (QC) samples of Sulfavant A during intra-day and inter-day analysis.

\begin{tabular}{|c|c|c|c|c|}
\hline & \multicolumn{4}{|c|}{ SULF A in $\mathrm{MeOH}$} \\
\hline & Nominal Concentration $\left(\mathrm{ngmL}^{-1}\right)$ & Mean \pm SD $^{a}$ & Accuracy $(\%)^{b}$ & Precision $(\mathrm{CV} \%)^{\mathrm{c}}$ \\
\hline \multirow{3}{*}{ T0 } & 30 & $27.8 \pm 2.2$ & 92.6 & 8.0 \\
\hline & 300 & $315.0 \pm 19.4$ & 105 & 6.1 \\
\hline & 1500 & $1247.8 \pm 69.2$ & 84.2 & 5.5 \\
\hline \multirow{3}{*}{$\begin{array}{c}\text { T12 } \\
\text { (Intra-day) }\end{array}$} & 30 & $27.7 \pm 1.14$ & 92.4 & 4.1 \\
\hline & 300 & $313.9 \pm 17.6$ & 104.6 & 5.6 \\
\hline & 1500 & $1265.2 \pm 27.6$ & 84.3 & 2.2 \\
\hline \multirow{5}{*}{$\begin{array}{c}\text { T48 } \\
\text { (Inter-day) }\end{array}$} & 30 & $30.7 \pm 1.5$ & 102.2 & 4.9 \\
\hline & 300 & $327.7 \pm 16.3$ & 109.2 & 5.0 \\
\hline & 1500 & $1353.6 \pm 15.0$ & 90.2 & 1.1 \\
\hline & \multicolumn{4}{|c|}{ SULF A in Matrix } \\
\hline & Nominal Concentration $\left(\mathrm{ngmL}^{-1}\right)$ & Mean \pm SD $^{a}$ & Accuracy $(\%)^{b}$ & Precision $(\mathrm{CV} \%)^{\mathrm{c}}$ \\
\hline \multirow{3}{*}{ T0 } & 30 & $26.0 \pm 2.2$ & 86.6 & 8.6 \\
\hline & 300 & $283.1 \pm 6.5$ & 94.4 & 2.3 \\
\hline & 1500 & $1459.9 \pm 79.7$ & 97.3 & 5.4 \\
\hline \multirow{3}{*}{$\begin{array}{c}\mathrm{T} 12 \\
\text { (Intra-day) }\end{array}$} & 30 & $28.6 \pm 2.0$ & 95.2 & 7.1 \\
\hline & 300 & $274.4 \pm 16.6$ & 91.5 & 6.1 \\
\hline & 1500 & $1457.3 \pm 84.1$ & 97.1 & 5.8 \\
\hline \multirow{3}{*}{$\begin{array}{c}\mathrm{T} 48 \\
\text { (Inter-day) }\end{array}$} & 30 & $27.0 \pm 1.2$ & 90.0 & 4.3 \\
\hline & 300 & $279.8 \pm 22.0$ & 93.3 & 7.9 \\
\hline & 1500 & $1432.5 \pm 46.2$ & 95.5 & 10.2 \\
\hline
\end{tabular}

${ }^{a} \mathrm{SD}=$ Standard Deviation $^{\mathrm{b}}$ [Measured mean concentration/ nominal concentration] $\times 100 .{ }^{\mathrm{c}}$ [Standard deviation/ measured mean concentration] $\times 100$.

This analytical method allowed for the detection of SULF A at nanomolar concentration (LOD was below $2.5 \mathrm{ngmL}^{-1}$ ) with a LOQ of $6.5 \mathrm{ngmL}^{-1}$, in both only $\mathrm{MeOH}$ and in the presence of matrix. Indeed, at the LOD the analyte in the samples can be identified by only HR-MS, but it cannot be quantitatively determined with appropriate precision and accuracy, whereas, at starting from the calibration point at $5 \mathrm{ngmL}^{-1}$, the peak of SULF 
A is also identifiable with MSMS and the signal appears to be defined and reproducible. Moreover, no carryover effect was detected during analysis of a blank sample after the injection of a standard sample at the highest calibration point $\left(2000 \mathrm{ngmL}^{-1}\right)$.

The reliability of this UHPLC-MS method was evaluated by measuring intra-day and inter-day accuracy and precision ( $\mathrm{n}=3$ in $\mathrm{MeOH} ; \mathrm{n}=5$ in matrix) of SULF A in quality control (QC) samples at three different concentrations $\left(30,300\right.$, and $\left.1500 \mathrm{ngmL}^{-1}\right)$. Table 3 reports the results in intra-day and inter-day accuracy and precision. The accuracy of QC samples ranged from 84.2 to $109.2 \%$, and precision ranged from 1.1 to $10.2 \%$ (Table 3). The overall assay accuracy (mean of accuracy estimates of all quality control samples) was $96 \%$ in $\mathrm{MeOH}$ and $93.4 \%$ in matrix, and overall assay precision (mean of precision estimates of all quality control samples) was $4.7 \%$ in $\mathrm{MeOH}$ and $6.4 \%$ in matrix.

Revalidation using two different batches of synthetic SULF A (namely, BS90A and BS90A1) was carried out at the same concentrations in the range between 2.5 and $2000 \mathrm{ngmL}^{-1}$ to further support the reliability of the method. The results showed an absolute reproducibility of the analysis with two superimposable calibration curves (BS90A: $y=31579 x$, $\mathrm{R}^{2}=$ 0.9999; BS90A1: $\mathrm{y}=31331 \mathrm{x}, \mathrm{R}^{2}=0.9999$ ).

\section{Conclusions}

An UHPLC-MS analytical procedure of SULF A, a 1,2-O-distearoyl-3-O- $\beta$-Dsulfoquinovosylglycerol with promising therapeutic application as a molecular adjuvant, was developed using a new deuterated analog $\left(\mathrm{d}_{70}\right.$-SULF $\left.\mathrm{A}\right)$ as an internal standard. The method was realized on a high-resolution benchtop Q-Exactive spectrometer using a UHPLC Kinete ${ }^{\circledR} 2.6 \mu \mathrm{m}$ PS C18 $100 \AA$ A, LC Column and a gradient elution with water buffered at $\mathrm{pH} 8$ and methanol. The sulfolipids (analyte and internal standard) were quantified in negative ion mode and the calibration curve covers a concentration range of $2.5-2000 \mathrm{ng} \mathrm{mL}^{-1}$ with an LLOQ of $6.5 \mathrm{ng} \mathrm{mL}^{-1}$. The new method was validated measuring the precision and accuracy on the quality control samples in the intra-day and inter-day study and its robustness was proven by applying it on a sample matrix.

The efficacy of this analytical method is of general interest to study sulfoglycolipids that are chemically correlated to SULF-A, and suggests that it could be extended for the study of both the physiological and biological role of this class of compounds. Furthermore, the short time of the UHPLC chromatographic analysis and sensitivity makes the procedure adapt to analysis of large number of biological samples.

Pharmacokinetic and drug metabolism tests are mandatory for expediting the progress of compounds with promising properties from discovery to development phase. Mass spectrometry is one of the key technologies in bioanalysis during preclinical and clinical studies [24]. The presented LC-MS method has been designed to provide a mechanistic understanding of the pharmacokinetics, pharmacodynamics, and toxicity of SULF-A. The excellent results in accuracy, sensitivity and reproducibility indicate that the analytical protocol can be utilized in pharmacological and translational research on this negativelycharged lipid, providing accurate results with a high value for further decisions in the drug development.

Author Contributions: Conceptualization, G.N., E.M., G.d. and A.F.; methodology, G.N., A.M.C. and M.Z.; standard preparation, M.Z., L.F. and C.G.; data curation, writing-original draft preparation, G.N.; writing-review and editing, E.M. and A.F. All authors have read and agreed to the published version of the manuscript.

Funding: This work was supported by the project "Antitumor Drugs and Vaccines from the Sea (ADViSE)" project (CUP B43D18000240007-SURF 17061BP000000011) funded by POR Campania FESR 2014-2020 "Technology Platform for Therapeutic Strategies against Cancer"-Action 1.1.2 and 1.2.2.

Acknowledgments: G.N., E.M. and A.F. thank BioSEArch SRL for the supply of sulfavant.

Conflicts of Interest: The authors declare no conflict of interest. 


\section{References}

1. Nuzzo, G.; Gallo, C.; D’Ippolito, G.; Manzo, E.; Ruocco, N.; Russo, E.; Carotenuto, Y.; Costantini, M.; Zupo, V.; Sardo, A.; et al. UPLC-MS/MS Identification of Sterol Sulfates in Marine Diatoms. Mar. Drugs 2018, 17, 10. [CrossRef]

2. Wood, P.L.; Siljander, H.; Knip, M. Lipidomics of human umbilical cord serum: Identification of unique sterol sulfates. Future Sci. OA 2017, 3, FSO193. [CrossRef]

3. Dias, I.H.; Ferreira, R.; Gruber, F.; Vitorino, R.; Rivas-Urbina, A.; Sanchez-Quesada, J.L.; Silva, J.V.; Fardilha, M.; De Freitas, V.; Reis, A. Sulfate-based lipids: Analysis of healthy human fluids and cell extracts. Chem. Phys. Lipids 2019, 221, 53-64. [CrossRef] [PubMed]

4. Gallo, C.; Nuzzo, G.; D’Ippolito, G.; Manzo, E.; Sardo, A.; Fontana, A. Sterol Sulfates and Sulfotransferases in Marine Diatoms. In Computer Methods, Part C; Elsevier BV: Amsterdam, The Netherlands, 2018; Volume 605, pp. 101-138.

5. Mirzaian, M.; Kramer, G.; Poorthuis, B.J.H.M. Quantification of sulfatides and lysosulfatides in tissues and body fluids by liquid chromatography-tandem mass spectrometry. J. Lipid Res. 2015, 56, 936-943. [CrossRef] [PubMed]

6. Moyano, A.L.; Li, G.; Lopez-Rosas, A.; Månsson, J.-E.; Van Breemen, R.B.; Givogri, M.I. Distribution of C16:0, C18:0, C24:1, and C24:0 sulfatides in central nervous system lipid rafts by quantitative ultra-high-pressure liquid chromatography tandem mass spectrometry. Anal. Biochem. 2014, 467, 31-39. [CrossRef] [PubMed]

7. Pintado-Sierra, M.; García-Álvarez, I.; Bribián, A.; Medina-Rodríguez, E.; Lebrón-Aguilar, R.; Garrido, L.; De Castro, F.; Fernández-Mayoralas, A.; Quintanilla-López, J.E. A comprehensive profiling of sulfatides in myelin from mouse brain using liquid chromatography coupled to high-resolution accurate tandem mass spectrometry. Anal. Chim. Acta 2017, 951, 89-98. [CrossRef]

8. Kongmanas, K.; Xu, H.; Yaghoubian, A.; Franchini, L.; Panza, L.; Ronchetti, F.; Faull, K.; Tanphaichitr, N. Quantification of seminolipid by LC-ESI-MS/MS-multiple reaction monitoring: Compensatory levels in Cgt mice. J. Lipid Res. 2010, 51, 3548-3558. [CrossRef]

9. Manzo, E.; Cutignano, A.; Pagano, D.; Gallo, C.; Barra, G.; Nuzzo, G.; Sansone, C.; Ianora, A.; Urbanek, K.; Fenoglio, D.; et al. A new marine-derived sulfoglycolipid triggers dendritic cell activation and immune adjuvant response. Sci. Rep. 2017, 7, 1-10. [CrossRef]

10. Manzo, E.; Gallo, C.; Fioretto, L.; Nuzzo, G.; Barra, G.; Pagano, D.; Krauss, I.R.; Paduano, L.; Ziaco, M.; DellaGreca, M.; et al. Diasteroselective Colloidal Self-Assembly Affects the Immunological Response of the Molecular Adjuvant Sulfavant. ACS Omega 2019, 4, 7807-7814. [CrossRef]

11. Manzo, E.; Fioretto, L.; Pagano, D.; Nuzzo, G.; Gallo, C.; De Palma, R.; Fontana, A. Chemical Synthesis of Marine-Derived Sulfoglycolipids, a New Class of Molecular Adjuvants. Mar. Drugs 2017, 15, 288. [CrossRef]

12. Ziaco, M.; Fioretto, L.; Nuzzo, G.; Fontana, A.; Manzo, E. Short Gram-Scale Synthesis of Sulfavant A. Org. Process. Res. Dev. 2020, 24, 2728-2733. [CrossRef]

13. Manzo, E.; Fioretto, L.; Gallo, C.; Ziaco, M.; Nuzzo, G.; D’Ippolito, G.; Borzacchiello, A.; Fabozzi, A.; De Palma, R.; Fontana, A. Preparation, Supramolecular Aggregation and Immunological Activity of the Bona Fide Vaccine Adjuvant Sulfavant S. Mar. Drugs 2020, 18, 451. [CrossRef]

14. Manzo, E.; Ciavatta, M.L.; Pagano, D.; Fontana, A. An efficient and versatile chemical synthesis of bioactive glyco-glycerolipids. Tetrahedron Lett. 2012, 53, 879-881. [CrossRef]

15. Manzo, E.; Ciavatta, M.L.; Pagano, D.; Fontana, A. Synthetic strategy for the preparation of bioactive galactoglycerolipids. Chem. J. Mold. 2011, 6, 27-29.

16. Vial, J.; Jardy, A. Experimental Comparison of the Different Approaches to Estimate LOD and LOQ of an HPLC Method. Anal. Chem. 1999, 71, 2672-2677. [CrossRef]

17. Cutignano, A.; Luongo, E.; Nuzzo, G.; Pagano, D.; Manzo, E.; Sardo, A.; Fontana, A. Profiling of complex lipids in marine microalgae by UHPLC/tandem mass spectrometry. Algal Res. 2016, 17, 348-358. [CrossRef]

18. De Nicolò, A.; Cantù, M.; D'Avolio, A. Matrix effect management in liquid chromatography mass spectrometry: The internal standard normalized matrix effect. Bioanalysis 2017, 9, 1093-1105. [CrossRef]

19. Schmidt, R.R.; Michel, J. Facile Synthesis of $\alpha$ - and $\beta-O-G l y c o s y l$ Imidates; Preparation of Glycosides and Disaccharides. Angew. Chem. Int. Ed. 1980, 19, 731-732. [CrossRef]

20. Schmidt, R.R. New Methods for the Synthesis of Glycosides and Oligosaccharides?Are There Alternatives to the Koenigs-Knorr Method? [New Synthetic Methods (56)]. Angew. Chem. Int. Ed. 1986, 25, 212-235. [CrossRef]

21. Zhao, Y.-Y.; Wu, S.-P.; Liu, S.; Zhang, Y.; Lin, R. Ultra-performance liquid chromatography-mass spectrometry as a sensitive and powerful technology in lipidomic applications. Chem. Interact. 2014, 220, 181-192. [CrossRef]

22. European Medicines Agency. An unacceptable choice. Prescrire Int. 2011, 20, 278.

23. Analytical Procedures and Methods Validation for Drugs and Biologics Guidance for Industry Analytical Procedures and Methods Validation for Drugs and Biologics Guidance for Industry. Available online: https:/ /www.fda.gov/regulatory-information/ search-fda-guidance-documents / analytical-procedures-and-methods-validation-drugs-and-biologics (accessed on 1 June 2020).

24. Avataneo, V.; D'Avolio, A.; Cusato, J.; Cantù, M.; De Nicolò, A. LC-MS application for therapeutic drug monitoring in alternative matrices. J. Pharm. Biomed. Anal. 2019, 166, 40-51. [CrossRef] [PubMed] 